\title{
Disagreement on agreement: person agreement between coordinated subjects and verbs in Dutch and German*
}

MARK TIMMERMANS, HERBERT SCHRIEFERS, TON DIJKSTRA, AND MARCO HAVERKORT

\section{Abstract}

Native speakers of Dutch and German reliably know how to combine the person features of a coordination of two singular elements into a new plural person feature. For example, a phrase like jij en de jongen (you [2nd singular] and the boy) becomes jullie (you [2nd plural]). However, anecdotal evidence suggests that despite this knowledge, speakers of Dutch and German have a strong tendency to treat the whole compound subject as 3rd person plural when computing person agreement between such a compound subject and a verb. In two language production experiments, we obtained results confirming this anecdotal evidence. Furthermore, the results show that the use of $3 r d$ person plural verbs does not depend on the order in which the 2nd and 3rd person elements occur in the compound subject (e.g. jij en de jongen vs. de jongen en jij). The results are interpreted in a framework assuming two alternative computational procedures for person agreement, a purely syntactic procedure and a conceptual-semantic procedure.

\section{Introduction}

In the last ten years or so, psycholinguistic studies of language production have shown an increasing interest in agreement phenomena. Two types of agreement relations have attracted most of the attention: number agreement between subject and verb (e.g. Bock 1995; Bock and Eberhard 1993; Vigliocco and Nicol 1998) and gender agreement between a noun and a gender-marked element like an adjective or a definite determiner (see Schriefers and Jescheniak 1999 for an overview). One common focus of this research concerns the question whether the computation of number and gender agreement in language production is carried out in a purely syntactic representation, or whether it is open to influences from 
the conceptual level and/or the eventual morphophonological realization of the relevant syntactic features.

Most studies have focused on a phenomenon called "proximity concord," as in the following example of an error in number agreement (1):

(1) The readiness of our conventional forces are at an all-time low.

In this case of proximity concord, there is an agreement source, the singular noun "readiness," and an agreement target - the verb. Correct agreement requires a singular verb. However, occasionally the verb will erroneously agree with the plural noun in the prepositional phrase "of our conventional forces," that is, the noun in the prepositional phrase is erroneously taken as the agreement source or agreement controller. Taking proximity concord as the point of departure, a number of studies have systematically varied semantic-conceptual or morphophonological properties of the subject noun or the local noun in order to determine whether and how these properties affect the probability of proximity concord.

In the present article, we will address another type of agreement relation - person agreement between a subject and a verb. At first sight, person agreement appears not to be an interesting issue; informal observation strongly suggests that person agreement in Dutch and German, the two languages studied in the present article, hardly ever derails. However, the topic becomes much more interesting when we consider subject noun phrases that consist of two coordinated (singular) elements that differ in person features, as in the following example from German (2):

(2) du und der Junge laufen/lauft

you (2nd singular) and the boy (3rd singular) run (3rd plural)/run (2nd plural)

We will refer to such subjects as "compound subjects" hereafter. A syntactic account of the computation of agreement appears to require a twostep procedure. First, the different singular person features of the two parts of the compound subject have to be combined into one plural person feature, and then this plural person feature functions as the agreement controller for the verb. For the first step, Dutch and German have the following rules (3):

(3) 1 st singular and 2 nd singular $=1$ st plural

1 st singular and $3 \mathrm{rd}$ singular $=1$ st plural

2nd singular and $3 \mathrm{rd}$ singular $=2$ nd plural

These so-called "resolution rules" (following the terminology proposed by Corbett 1983, 1991) derive the agreement features of a compound NP on the basis of the features of the individuals conjuncts. Corbett (1983) 
provides an extensive discussion of resolution rules for person and number. In (3), two sets of resolution rules can be distinguished: one for number and one for gender. The number rule states that compound subjects require plural. The person rules state that "the 1st person takes precedence over the 2nd person, and the 2nd over the 3rd" (Corbett 1983: 175-176). When compound subjects could trigger more than one resolution rule (e.g. number and person, as in [2] and [3] above), the normal choice is to apply all the appropriate resolution rules (e.g. number and person), or to apply no resolution rule and to have agreement with one of the conjuncts only. In the latter case, agreement is usually with the nearest conjunct. Furthermore, Corbett (1983) notes that exceptions to these principles can be found, and refers in this context to German and French. (2) above provides an example of such an exception. In this example, the 2nd person plural and the 3rd person plural verb appear to be equally acceptable. Note that in case of the 3rd person plural verb, number resolution applies while person resolution does not.

The rules given above are (implicitly) known to every native speaker of Dutch and German. This is easily verified by asking native speakers of Dutch or German to replace a compound subject coordination by a plural pronoun. Thus, for example, native speakers of German will always and without any hesitation replace the compound subject $d u$ und der Junge (you [2nd singular] and the boy) with $i h r$ (you [2nd plural]). We performed such a simple replacement test with ten native speakers of Dutch and ten native speakers of German. All responses followed the rules given above.

However, anecdotal evidence suggests that native speakers of Dutch and German do not necessarily apply this knowledge. The prototypical case are sentences with a compound subject with two singular noun phrases differing in person (e.g. Drosdowski et al. 1972; Findgren 1976). In these cases, speakers appear to be unsure about which person feature the verb should have. Thus, native speakers of German will produce a sentence like $d u$ und der Junge, ihr geht (you [2nd singular] and the boy, you [2nd plural] walk [2nd plural]), while they will not produce a sentence like $d u$ und der Junge, ihr gehen (you [2nd singular] and the boy, you walk [3rd plural]). However, they do produce sentences like du und der Junge gehen (you [2nd singular] and the boy gehen [3rd plural]). It has even been suggested that they prefer the third person plural verb over the second person plural verb in the latter type of sentence (Drosdowski et al. 1972). If this were actually the case, we would be confronted with a situation in which speakers clearly have the knowledge about the rules given in (3), but they do not apply this knowledge when they provide a verb with a compound subject. This would be in clear contrast with other types 
of resolution rules. For example, the resolution rules for gender agreement between a compound subject and a predicative adjective in French are (almost) always followed by native speakers of French (e.g. la fille est *competent (m.sg.)/competente (f.sg) 'the girl is competent,' but [le garcon et la fille] sont competents (m.pl.)/*competentes (f.pl.) 'the boy and the girl are competent').

However, as stated above, the corresponding evidence is only anecdotal. In the present study, we set out to obtain systematic evidence by eliciting sentences with compound subjects in native speakers of Dutch and German. The primary goal of our experiments was to establish whether the mentioned anecdotal evidence can be confirmed. Furthermore, establishing corresponding evidence in two languages, German and Dutch, is important because the anecdotal evidence on deviations of person agreement resolution rules has until now been constrained to German (and French, cf. Corbett 1983). In addition, we will explore a number of potential factors that might affect the choice of verb person by systematically comparing different types of compound subjects. Before describing these factors, we will briefly provide some information about person agreement in Dutch and German.

Table 1 gives the system of Dutch (nominative) personal pronouns and the corresponding verb inflection. For each pronoun, two inflected verbs are provided: a reflexive verb and a nonreflexive verb. As can be seen, the inflection of Dutch plural verbs does not mark person. However, person is marked on the plural reflexive pronouns. The reflexive verb in Table 1 is the Dutch equivalent of "to wash oneself," the nonreflexive verb is the Dutch equivalent of "to walk."

Table 1. Personal pronouns and person agreement on the verb in Dutch

\begin{tabular}{llllll}
\hline Person & Singular & & & \multicolumn{2}{l}{ Plural } \\
\cline { 2 - 3 } & nonreflexive & reflexive & & nonreflexive & reflexive \\
\hline First & ik loop & ik was me & & wij lopen & wij wassen ons \\
Second & jjj loopt & jij wast je & & jullie lopen & jullie wassen je \\
Third Feminine & zij loopt & zij wast zich & & zij lopen & zij wassen zich \\
Third Masculine & hij loopt & hij wast zich & & \\
Third Neuter & het loopt & het wast zich & & \\
\hline
\end{tabular}

In German, by contrast, verbs take different inflections for the 1st and 3rd person plural on the one hand, and for the 2 nd person plural on the other (see Table 2). 
Table 2. Personal pronouns and person agreement on the verb in German

\begin{tabular}{lll}
\hline Person & Singular & Plural \\
\hline First & ich gehe & wir gehen \\
Second & du gehst & ihr geht \\
Third Feminine & sie geht & sie gehen \\
Third Masculine & er geht & \\
Third Neuter & es geht & \\
\hline
\end{tabular}

In the experiments reported below, we presented native speakers of Dutch or German with compound subjects consisting of a second and a third person pronoun, or of a second person pronoun and a full noun phrase. The speakers' task was to complete these sentence beginnings (hereafter called "preambles," following the terminology from studies on number agreement) as quickly as possible to a full sentence. The dependent variable was the choice of verb-person in the sentence completions. In the critical preambles, we crossed two factors. The first factor concerned the order of the two parts of the compound subject (2nd person followed by 3 rd person vs. 3rd person followed by 2 nd person). This manipulation allows to test two competing hypotheses. According to the first hypothesis, the choice of a 2 nd or 3rd person plural verb is codetermined by the surface order in which the two person features occur in the preamble. More specifically, this proximity hypothesis predicts that speakers produce more 2nd person plural verbs when the 2nd person part of the compound subject is in second position, and more 3rd person plural verbs when the 3rd person plural part is in second position.

The second hypothesis is based on recent developments in syntactic theory and leads to the opposite prediction of a proximity effect. Traditionally, coordination was conceived of as a symmetrical structure in which the conjoined elements occupy parallel positions in the syntactic structure. For the case of the specific type of coordination of interest in the present study, this structure is given in (4):

(4)

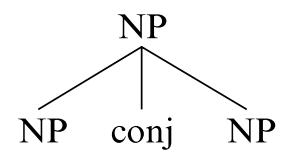

However, more recently, a structure has been proposed in which the conjoined elements do not occupy parallel positions (e.g. Heijden 1999; Kayne 1994; Munn 1993). The corresponding structure is given in (5). 
(5)

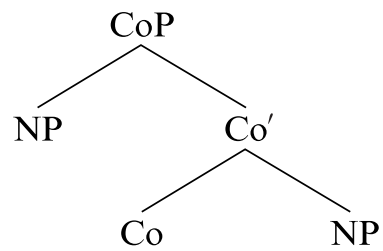

This change was motivated by both theoretical and empirical considerations. Following X-bar theory, in this structure, the coordinating conjunction $(\mathrm{Co})$ acts as the head of the coordinate structure, which otherwise would be headless. The second conjunct forms a constituent with the conjunction. Thus, in such a structure the two conjuncts no longer occupy parallel, symmetrical positions; there is a clear hierarchical difference. Such a difference is supported by a couple of empirical observations. We will, by way of example, only mention some empirical facts speaking in favor of this structure.

One empirical argument in favor of an asymmetric structure, in which the second conjunct forms a constituent with the conjunction, is that these two elements behave more as a unit than the first conjunct and the conjunction. They can be separated from the first conjunct, for instance:

(6) I saw John yesterday, and his dog

Moreover, multiple elements can be coordinated, but the conjunction must always precede the last element, also indicating that this element has a stronger relation with the conjunction than the others.

(7) a. John bought a book, a $\mathrm{CD}$, and a magazine

b. *John bought a book and a $\mathrm{CD}$, a magazine

A conjunction can also open a sentence, but it cannot be the last word of a sentence:

(8) a. John left. And he did not even say goodbye

b. *John left and. He did not even say goodbye

A final argument comes from the interpretation of pronouns (cf. Munn 1993; Heijden 1999). Consider the following pair of coordinate structures:

(9) a. John', 's dog and he $\mathrm{i}_{\mathrm{i}}$ went for a walk

b. ${ }^{*} \mathrm{He}_{\mathrm{i}}$ and $\mathrm{John}_{\mathrm{i}}$ 's dog went for a walk

In (9a), the pronoun he can co-refer with the proper name John, that is, they can refer to the same person in reality (this is indicated by the subscripts); in (4b) such an interpretation is clearly excluded: he must refer to someone other than John. It is independently known that a coreferential interpretation of a pronoun and a proper name can only occur under 
certain conditions, whereby the pronoun cannot be in a hierarchically higher position than the proper name. This can be illustrated by looking at the relation between subject and object, where the former is hierarchically higher than the latter; here the same asymmetry as in (9) shows up:

$$
\begin{aligned}
& \text { a. } \mathrm{John}_{\mathrm{i}} \text { patted his } \mathrm{s}_{\mathrm{i}} \mathrm{dog} \\
& \text { b. }{ }^{*} \mathrm{He}_{\mathrm{i}} \text { patted John }{ }_{\mathrm{i}} \text { 's dog }
\end{aligned}
$$

In a symmetrical structure for coordination, there is no hierarchical difference between the two, and hence, an asymmetry as the one in (9) is unexpected and cannot be explained. An asymmetrical structure, on the other hand, can straightforwardly account for these facts: if the pronoun is the second conjunct, it is not in a hierarchically higher position than the proper name, and a coreferential interpretation is allowed, as in (9a). If, however, the pronoun is the first conjunct, as in (9b), it is in a hierarchically higher position than the proper name and a coreferential interpretation is thus excluded.

$$
\begin{aligned}
& \text { a. [CoP [NP John's dog] [Co' [Co and] [NP he]]] } \\
& \text { b. [CoP [NP he] [Co' [Co and] [NP John's dog]]] }
\end{aligned}
$$

Interestingly, an asymmetric structure for coordination has consequences for agreement processes of the type studied in the present paper. It predicts that the first conjunct, which occupies the specifier position, has a special status. Its features will be passed on to the head, Co, by means of specifier-head agreement, and from there they percolate up to the maximal projection, CoP. As a consequence, the person feature of the first conjunct should be a stronger determinant of the person feature of the verb than the person feature of the second conjunct, thus yielding precisely the opposite prediction from a proximity account.

The manipulation of the order of the two parts of the compound subject was crossed with an additional manipulation in which we realized the 3rd person plural part of the compound subject either by a 3rd person singular pronoun or by a full noun phrase. This allows us to test whether a full noun phrase is a more prototypical, and thus more dominant, case of a 3 rd person singular than a 3 rd person singular pronoun. If this were the case, a compound subject with a full noun phrase should yield more 3rd person plural verbs than a compound subject with a 3rd person singular pronoun. The resulting four conditions were complemented by a baseline condition in which the preamble was a 2 nd person plural pronoun (ihr in the case of German, and jullie in the case of Dutch).

In summary, our experiments investigated three main hypotheses. First, do speakers apply their knowledge about resolution rules for person, that is, that a coordination of $2 \mathrm{nd}$ and $3 \mathrm{rd}$ person actually results 
in the feature 2 nd person plural, when producing sentences with a compound subject? Or does the person agreement process systematically deviate from these resolution rules even though they are known to the speakers? Put differently, the first goal was to provide a systematic empirical test of the anecdotal evidence cited above. Second, is the process of person agreement computation affected by the order in which the two parts of the compound subject occur? With respect to this question, we contrast the two hypotheses introduced above. And third, do 3rd person plural pronouns and full noun phrases behave differently in the process of person agreement computation? In the following, we will report two experiments testing these issues. With these empirical data in hand, we will then discuss some implications for the computation of person agreement in speech production.

\section{Experiment 1: person agreement in Dutch}

As pointed out above, person agreement on plural verbs in Dutch only becomes visible on reflexive pronouns. In the first experiment, we asked participants to complete preambles by means of reflexive verbs that can only be used with a reflexive pronoun. Participants first saw a verb to be used in their response, which was then followed by an auditory presentation of the preamble consisting of a compound subject or of the 2nd person plural pronoun (baseline). The participants' task consisted of repeating the preamble aloud, and inflecting and uttering the visually presented verb such that a simple grammatical sentence resulted. Because the goal of the experiment was to see which reflexive pronoun participants produce spontaneously, the number of such critical trials should be low across the entire experiment. Otherwise, one would run the risk that participants become aware of the purpose of the experiment and thus no longer provide the first response that comes to their mind. Informal pilot studies confirmed these considerations. Therefore, each participant received only one critical trial in each of the five critical conditions. These five critical trials were embedded in a large number of filler trials. The percentage of critical trials was set to $10 \%$ across the entire experiment. In addition, only a small proportion of the verbs on the filler trials required a reflexive pronoun.

\subsection{Method}

2.1.1. Participants. Forty undergraduate students at the University of Nijmegen participated in the experiment. They were all native speakers of 
Dutch and had normal or corrected-to-normal vision. All participants were paid for their participation or received course credit.

2.1.2. Design. Participants were asked to complete 52 preambles. There were five critical trials with verbs that require a reflexive pronoun, eight noncritical trials with verbs that allow but do not require a reflexive pronouns, and 39 noncritical filler trials with verbs that are not accompanied by a reflexive pronoun. The critical preambles were:

$$
\begin{aligned}
& \text { [1] jullie } \\
& {[2] \text { jij en hij }} \\
& {[3] \text { hij en jij }} \\
& {[4] \text { jij en de NPsing }} \\
& \text { [5] de NPsing en jij }
\end{aligned}
$$

According to the rules given above, in Dutch, the reflexive pronoun for all five conditions should be je (you [pl.]) or jullie (you [pl.]). In addition, there were eight filler trials with compound subjects and (optionally) reflexive verbs: $i k$ en $j i j$ (I and you [sg.]), ik en hij (I and he), ik en de NPsing (I and the NPsing), and hij en de NPsing (he and the NPsing), and the same preambles with the two parts of the compound subject in reversed order. Finally, there were 31 filler trials with preambles with simple subjects and nonreflexive verbs: $i k$ (I) (7 trials), jij (you [sg.]) (4 trials), hij (he) (4 trials), a singular noun phrase (6 trials), wij (we) (3 trials), jullie (you [pl.]) (3 trials), and a plural noun phrase (4 trials). In addition, all preambles with a compound subject were also used once in combination with the nonreflexive filler verbs except for the combinations $i k$ en de NPsing (I and the NPsing), hij en de NPsing (he and the NPsing), and their reversals.

The critical preambles were combined with the following five verbs: (1) zich bedrinken 'to fuddle oneself,' (2) zich misdragen 'to misbehave,' (3) zich schamen 'to feel ashamed,' (4) zich vergissen 'to make a mistake,' and (5) zich verspreken 'to make a slip of the tongue.' Note that these verbs all require an obligatory reflexive pronoun in Dutch.

Forty lists were constructed such that every participant received all preambles and all verbs. The reflexive verbs were rotated across participants such that every critical preamble preceded every critical verb eight times after a full rotation of the design.

2.1.3. Procedure. Participants received written instructions asking them to repeat the preamble and to complete it using the verbs that were presented visually. Participants were informed about the presence of verbs that required reflexive pronouns. In such cases, they were to fill in 
the appropriate reflexive pronoun themselves. Thus, a complete sentence consisted of a subject and a main verb for the nonreflexive verb trials, and a subject, a main verb, and a reflexive pronoun for the reflexive verb trials.

Each trial started with a small fixation cross in white in the center of a computer monitor. After $800 \mathrm{~ms}$, the fixation cross disappeared and the screen was blank for $200 \mathrm{~ms}$. Following this, the verb was presented in the center of the screen. After $1000 \mathrm{~ms}$, the verb disappeared and the sentence fragment was presented auditorily. Participants responded by repeating the preamble and adding either a verb, or a verb and a reflexive pronoun (depending on the type of trial). A trial lasted about 4500$5000 \mathrm{~ms}$ depending on the length of the sentence fragments.

Before the actual experiment began, participants received a training set of ten trials. These trials were a representative sample of the trials in the experiment except for the omission of critical preambles with reflexive verbs.

During the experiment, the experimenter scored all reflexives participants uttered. Hesitations, errors, and omissions of reflexive pronouns were also scored.

Stimuli were presented on an Intel Pentium $166 \mathrm{MHz}$ computer. The fixation cross and the verbs were presented in the center of the screen in white against a dark-gray background. The verbs of the critical trials, that is, those obligatorily requiring a reflexive pronoun, and those of the filler trials with optional reflexive pronoun were presented without a reflexive pronoun (e.g. bedrinken for the obligatorily reflexive verb zich bedrinken). This was done because the full infinitive (citation) form of these verbs would contain the reflexive pronoun zich, which is homophonous with the 3 rd person plural reflexive pronoun. Thus, presenting the full infinitive forms of the reflexive verbs might introduce a tendency to simply reuse the reflexive pronoun of this infinitive form. Because the verbs on the critical trials were obligatorily reflexive, presenting only the verb (without the reflexive pronoun of the citation form) was sufficient to trigger production of a reflexive pronoun in the response.

Participants sat in a dimly lit, soundproof room at a distance of about $80 \mathrm{~cm}$ from the monitor. Responses were recorded using a microphone placed about $50 \mathrm{~cm}$ in front of the participant. The preambles were read aloud by a female speaker and digitized with a computer. Playback of the preambles was realized via a Yamaha MS20s active sound monitor.

\subsection{Results and discussion}

Table 3 gives the number of choices for the plural reflexive pronouns je/ jullie (2nd person plural) and zich (3rd person plural) for the five critical 
Table 3. Number of reflexive pronouns observed for critical trials in Experiment 1 (Dutch)

\begin{tabular}{lllllll}
\hline Condition & Preamble & \multicolumn{2}{l}{ Uttered reflexive } \\
\cline { 3 - 7 } & & je/jullie & & zich & & Error \\
\hline$[1]$ & jullie & 32 & $(86)$ & 5 & $(14)$ & 3 \\
{$[2]$} & jij en hij & 15 & $(39)$ & 23 & $(61)$ & 2 \\
{$[3]$} & hij en jij & 18 & $(50)$ & 18 & $(50)$ & 4 \\
{$[4]$} & jij en NPsing & 15 & $(40)$ & 22 & $(60)$ & 3 \\
{$[5]$} & NPsing en jij & 16 & $(43)$ & 21 & $(57)$ & 3 \\
\hline
\end{tabular}

Note. Percentage of valid responses per condition in parentheses (excluding errors).

conditions. Note that if speakers would strictly stick to the resolution rules given above, the vast majority of responses should be je/jullie.

The data are based on observations collected from 40 participants. As we collected only one observation per participant per critical preamble, the number of observations for every condition always sums up to 40 . The column "error" lumps together all responses that could not be scored as belonging to one of the possible reflexives, including responses with omissions of the reflexive pronoun, no response at all, and hesitations during speech. The percentage of the reflexive pronouns within a condition (excluding responses coded as errors) is given in parentheses.

The results were analyzed as follows. First, we determined whether the baseline condition (i.e. Condition [1]) deviated from the other four conditions in the number of usage of the reflexive pronoun je/jullie. A corresponding Chi-square test gave a Chi-square of 32.19 which, with four degrees of freedom, is highly significant.

Next, we compared all possible combinations of conditions [2] through [5] for each of the two response categories ("je/jullie," "zich"). None of these comparisons yielded a significant effect.

Before turning to a discussion of the results, we will address one additional point in the results of Experiment 1. It could be the case that the pattern in Table 3 is simply the result of pooling together two groups of speakers with different "speaking styles," with one group always opting for the 2nd person reflexive, and another group always opting for the 3rd person reflexive. We checked for this possibility in the following way. As each participant had one critical trial in each of the conditions [2] to [5], a given participant could produce a maximum of 4 responses with a 3rd person reflexive pronoun, and a minimum of 0 responses with a $3 \mathrm{rd}$ person reflexive pronoun. When we compute how the participants are actually distributed across this range of 3rd person responses, we get the following picture. Thirteen out of 40 participants show completely ho- 
mogeneous responses across the four conditions [2] to [5], with six participants never providing a $3 \mathrm{rd}$ person response, and seven participants giving a $3 \mathrm{rd}$ person response on all four occasions. The remaining 27 participants show intraindividual response variability, with six participants providing one $3 \mathrm{rd}$ person response out of four possible ones, thirteen participants providing two 3rd person responses each, and eight participants providing three $3 \mathrm{rd}$ person responses each. This distribution thus shows a strong tendency for intraindividual variability in the use of $3 \mathrm{rd}$ person responses, and thus speaks against the assumption that the results are due to a pooling together of two groups of speakers with different "speaking styles."

The results so far can be summarized as follows. First, although there is a substantial number of responses following the resolution rule for combining the different singular person features into a 2 nd person plural feature (the "je/jullie" responses), the majority of participants chooses the 3rd person plural reflexive. Thus, it appears that in Dutch there are two different ways to compute person agreement between a compound subject and a verb. The first way is the two-step procedure described above, that is, the different singular person features of the compound subject are combined according to the rules given in (3), and the resulting plural person feature is used as the agreement controller for the reflexive. However, there must also be a second computational route which leads to the choice of a 3rd person plural reflexive. Below, we will offer some speculation as to what this route might be. For the moment, we can conclude that the use of the $3 \mathrm{rd}$ person plural reflexive is not simply due to a proximity effect. Furthermore, it is not affected by whether the 3rd person singular element in the subject coordination is a full noun or a 3 rd person singular pronoun. Finally, the use of a 2 nd or 3 rd person reflexive is not just a question of interindividual differences. Rather, there is considerable intraindividual variability in the use of $2 \mathrm{nd}$ and $3 \mathrm{rd}$ person.

As pointed out in the introduction, Dutch and German have analogous resolution rules for combining a coordination of two singular person features into a new plural person feature. However, while in Dutch the result of person agreement computation only becomes visible on reflexive verbs, in German, it also becomes visible on the inflectional ending of the verb (see Table 2). Therefore, we conducted a comparable experiment in German. This experiment allowed to test whether the pattern of results obtained for Dutch is specific for reflexives, or whether it also applies to verb inflections. Furthermore, because German marks the difference between 2nd and 3rd person plural on every verb, we could use a procedure in which we did not have to specify the verbs to be used by the participants. 


\section{Experiment 2: person agreement in German}

The critical trials were the German counterparts of the preambles used in the experiment on Dutch:
[1] $i h r$
[2] du und er
[3] er und $d u$
[4] du und der Junge
[5] der Junge und du

\author{
'you [pl.]' \\ 'you [sg.] and he' \\ 'he and you [sg.]' \\ 'you [sg.] and the boy' \\ 'the boy and you [sg.]'
}

In the present experiment, participants were not given any additional instructions except that they should repeat and complete the sentence beginning. This implies that participants could also proceed by first repeating the preamble, then summarizing the two coordinated elements in the appropriate plural pronoun, and then to complete it to a full sentence. This would lead to utterances like (14) ${ }^{1}$ :

(14) du und der Junge, ihr solltet jetzt nach Hause gehen you [2nd sg.] and the boy, you [2nd pl.] must [2nd pl] now to home go

'You and the boy, you must go home now.'

Of course, such utterances will not provide the necessary data for the computation of person agreement between a compound subject and the verb. Rather, as we know that speakers reliably know that such a coordination is equivalent to the 2 nd person plural pronoun $i h r$, one would expect that in this case they will also use a 2 nd person plural verb form. As we had no advance knowledge as to how often such a response pattern might occur, we also included sentence beginnings which should suppress such a response tendency. The corresponding critical sentence beginnings are given in (15):
[1] weil ihr
[2] weil du und er
[3] weil er und du
[4] weil du und der Junge
[5] weil der Junge und du

Theoretically, participants could contract the two coordinated elements into one plural noun also in these cases. However, when doing so, a grammatical utterance would require them to also repeat the subordinating conjunction weil. Thus, while an utterance like weil du und der Junge, weil ihr böse seid (because you [2nd sg.] and the boy, because you [2nd pl.] are [2nd pl.] angry) is perfectly grammatical, an utterance like weil du und 
der Junge, ihr böse seid (because you [2nd sg.] and the boy, you [2nd pl.] are [2nd pl.] angry) is clearly ungrammatical. Because using the 2 nd person plural pronoun would imply the need for repeating the subordinating conjunction, we expected that these sentence preambles would suppress the tendency to use this option. We will refer to the sentence beginnings in (13) as "main clause preambles" and to the sentence beginnings in (15) as "subordinate clause preambles" hereafter.

\subsection{Method}

3.1.1. Participants. Sixty native speakers of German, most of them students at the Humboldt University in Berlin, participated in the experiment.

3.1.2. Design. The critical trials consisted of the ten sentence beginnings given in (13) and (15). Every participant heard all sentence beginnings once in the course of the experiment. The critical trials were embedded in a list of 70 other sentence beginnings. These 70 sentence beginnings were structurally different. Most of these 70 sentence beginnings consisted of a singular or a plural subject noun, followed by additional material (either a prepositional phrase or a relative clause). A random order of the 80 items was determined under the restriction that the critical trials were separated by at least four other trials. A second randomization was derived by presenting this list in reversed order. An equal number of participants was assigned to the two randomizations.

3.1.3. Procedure. The materials were recorded on tape by a female native speaker of German. The sentence beginnings were presented one by one by the experimenter. After each sentence beginning, the tape was stopped until the participant had repeated and completed the sentence beginning. The participants' responses were recorded with a second tape recorder for later scoring.

\subsection{Results and discussion}

All responses were scored as in the preceding experiment. Table 4 gives the number of 3 rd person plural responses, of 2 nd person plural responses, and the number of errors for the five different sentence beginnings [1] through [5] for the main clause preambles. ${ }^{2}$ 
Table 4. Number of inflections observed for critical trials in Experiment 2 (German - main clause)

\begin{tabular}{llrrrrr}
\hline Condition & Preamble & \multicolumn{2}{l}{ Uttered inflection } \\
\cline { 3 - 7 } & & \multicolumn{2}{l}{ geht (2nd pl.) } & gehen (3rd pl.) & Error \\
\hline$[1]$ & ihr & 58 & $(100)$ & 0 & $(0)$ & 2 \\
{$[2]$} & du und er & 7 & $(22)$ & 25 & $(78)$ & 28 \\
{$[3]$} & er und du & 5 & $(24)$ & 16 & $(76)$ & 39 \\
{$[4]$} & du und NPsing & 7 & $(27)$ & 19 & $(73)$ & 34 \\
{$[5]$} & NPsing und du & 13 & $(37)$ & 22 & $(63)$ & 25 \\
\hline
\end{tabular}

Note. Percentage of valid responses per condition in parentheses (excluding errors).

The results were analyzed in the same way as in Experiment 1. The baseline condition ("ihr") showed a significantly higher number of 2 nd person plural verbs than the four remaining conditions with compound subjects (Chi-square $=173.03$ at four degrees of freedom). In the four compound subject conditions [2] to [5], the 3rd person plural verbs are more frequent than 2 nd person plural verbs. Sign-tests showed that the four compound subject conditions did not differ with respect to the number of 3rd person verbs. However, Table 4 also shows that the majority of responses in the compound subject conditions is classified as errors. Here, it has to be kept in mind that "error" is a broad category including all responses which could not uniquely be classified as 2 nd or 3 rd person verb responses directly following the compound subject. This category thus also includes the (grammatical) responses in which participants repeat the preamble, summarize the compound subject by a plural pronoun, and then add the sentence completion (e.g. "du und er, ihr...." 'you (2nd sg) and he, you (2nd pl),' a resumptive pronoun construction, which is a special case of the so-called "contrastive left dislocation construction"). This was the case for $83 \%$ of all errors in the main clause conditions. In all of these responses, participants produced the 2 nd person plural pronoun $i h r$ after having repeated the sentence beginning, and then continued with a 2 nd person plural verb.

Table 5 shows the results for the subordinate clause condition.

First, as is clear from Table 5, the subordinate clause preambles have much less responses categorized as errors. This is due to the fact that in the subordinate clause condition, participants never summarize the preamble as a 2nd person plural pronoun before producing the sentence completion. As in the preceding experiments, the baseline condition ("ihr") showed a significantly higher number of 2 nd person plural verbs than the four remaining conditions with compound subjects (Chi-square 
Table 5. Number of inflections observed for critical trials in Experiment 2 (German subordinate clause)

\begin{tabular}{llllrlr}
\hline Condition & Preamble & \multicolumn{4}{l}{ Uttered inflection } \\
\cline { 3 - 6 } & & \multicolumn{2}{l}{ geht (2nd pl.) } & gehen (3rd pl.) & Error \\
\hline$[1]$ & ihr & 56 & $(100)$ & 0 & $(0)$ & 4 \\
{$[2]$} & du und er & 12 & $(22)$ & 43 & $(78)$ & 5 \\
{$[3]$} & er und du & 9 & $(17)$ & 44 & $(83)$ & 7 \\
{$[4]$} & du und NPsing & 9 & $(18)$ & 40 & $(82)$ & 11 \\
{$[5]$} & NPsing und du & 9 & $(15)$ & 50 & $(85)$ & 1 \\
\hline
\end{tabular}

Note. Percentage of valid responses per condition in parentheses (excluding errors).

$=1752.9$ at four degrees of freedom). In the four compound subject conditions [2] to [5], the 3rd person plural verbs are much more frequent than 2nd person plural verbs. Sign-tests showed that the four compound subject conditions did not differ with respect to the number of $3 \mathrm{rd}$ person verbs.

The distribution of participants across the possible range of $3 \mathrm{rd}$ person responses (minimum 0, maximum 4) gives the following picture. Thirtyfour out of 60 participants show completely homogeneous responses across the four conditions [2] to [5], with three participants never providing a 3rd person response, and 31 participants giving a $3 \mathrm{rd}$ person response on all four occasions. The remaining 26 participants show intraindividual response variability, with ten participants providing one $3 \mathrm{rd}$ person response out of four possible ones, five participants providing two 3rd person responses each, and eleven participants providing three 3rd person responses each. This distribution differs from those obtained for Dutch; the proportion of participants who consistently give 3rd person responses (31 out of 60 participants) is higher than in the corresponding experiment in Dutch (13 out of 40 participants). We have no obvious explanation for this difference. Nevertheless, as in the preceding experiment, this analysis shows that the overall pattern of results is not the result of lumping together the data from two subgroups with one subgroup exclusively providing 3 rd person responses, and the other subgroup exclusively giving 2 nd person responses. Rather, there is again intraindividual variability in the use of 3 rd person responses in approximately half of the participants.

In summary, the present experiment shows the following. First, as in Dutch, there is a strong tendency to produce 3rd person plural verbs after compound subjects consisting of a 2 nd and a 3 rd person element. 
For verb inflection in German, this tendency is even stronger than for the choice of reflexive pronouns in Dutch. Second, there is again no sign of a proximity effect. If anything, the descriptive distribution of 3rd person plural responses goes in the opposite direction of a proximity effect. Third, as in the preceding experiments, the pattern of responses does not differ between compound subjects with a 3rd person singular pronoun and compound subjects with a singular full noun phrase. Fourth, when possible, speakers of German show a strong tendency to summarize the compound subject into one 2 nd person plural pronoun. The latter result suggests that speakers are somehow aware of the fact that there are two conflicting ways for computing person agreement, and try to avoid this conflict when possible by explicitly summarizing the two parts of the compound subject as one plural pronoun.

\section{General discussion}

The results of the present experiments reveal a curious phenomenon. Although native speakers of Dutch and German clearly know that the coordination of a 2 nd and a 3 rd person singular element has the feature 2nd person plural, they frequently treat such coordinations as 3rd person plural when they compute the person agreement between such a coordination and a verb "directly," that is, without first contracting the two singular pronouns into a 2 nd person plural pronoun. In fact, this tendency to use the 3rd person plural on the verb or on the reflexive is the dominant response pattern. This is particularly clear for German, but it also holds for the choice of person marked reflexive pronouns in Dutch. Furthermore, this tendency is modulated neither by the proximity between the 3rd person singular element and the verb, nor by the status of the 3 rd person singular element as a pronoun or a full noun. With respect to proximity, however, we have to keep in mind the alternative hypothesis introduced above, which is based on the assumption of an asymmetrical structure of coordinations. Such an asymmetrical structure predicts the opposite of a proximity effect, namely, a dominance of the first part of the coordination in person agreement. Such a "reversed proximity" effect would thus be due to the fact that, structurally, the first part of the coordination is "closer" to the verb than the second part of the coordination. The data do not provide support for this alternative hypothesis. However, one could argue that the absence of any effect of the order of the parts of the coordination is the net result of a proximity effect that is due to linear order, and a "reversed proximity" effect that is due to an asymmetric structure of coordinations. Although possible in principle, it is difficult 
to imagine an agreement process that is sensitive to both linear order and structural relations at the same time.

Before turning to a discussion of the implications for psycholinguistic models of language production, we will first address potential caveats.

First, one might object that the use of pronouns was highly artificial because no referents were introduced by some kind of a context sentence. Unfortunately, for the type of preambles used in the present experiment, an adequate context sentence introducing a referent for the second person plural pronoun appears to be impossible, unless one would introduce an (artificial) conversational setting in which the critical sentences have to be produced. However, the same agreement phenomena as obtained in our experiments are also found in written language (e.g. Findgren 1976) where the critical sentences are embedded in context.

Second, one might wonder whether the condition with the 2nd person plural pronoun as preamble is an adequate baseline, as the preambles in this condition differ from those in the critical conditions in aspects like length and syntactic complexity. However, similar differences hold for the critical conditions with the 3 rd person element being a pronoun or a full noun phrase, but these differences do not affect the observed pattern of results. Finally, even when we do not consider the baseline, the results are still clear. The four critical conditions show that speakers of Dutch and German prefer the 3rd person plural over the 2nd person plural for the verb even though they do know the resolution rules for person in compound subjects.

A third caveat concerns the potential role of formal language education. One might be tempted to argue that the pattern of results is due to language education during schooling. However, formal language training stresses precisely the rules mentioned above, if it addresses this topic at all. Thus, if anything, formal language training should favor 2 nd person plural responses, and thus, without formal language training, the frequency of usage of the 3rd person plural would actually be even more dominant than it already is in the present data.

A final caveat concerns the fact that, in German, the 2nd person plural of a verb also functions as the imperative plural from (e.g. Geht! 'Walk!'). Thus, there is the possibility that the preference of a $3 \mathrm{rd}$ person plural verb is actually due to a tendency to avoid this from. However, this argument does not hold for present-day Dutch, where the 2nd person plural form is not used as the plural imperative form. Nevertheless, we obtained highly comparable results in Dutch and German.

A related proposal for accounting for the deviations from person resolution rules in German has been put forward by Corbett (1983: 182-183). He suggests that the verb inflection -en (1st and 3rd person plural) is a 
clear marker for plurality, while the ending -(e)t (2nd plural) is in some instances indistinguishable from the $3 \mathrm{rd}$ person singular (e.g. er geht 'he walks,' ihr geht 'you (2nd plural) walk'). However, this argument does not hold for reflexive pronouns in Dutch were the reflexive je and the reflexive zich can both function in singular and plural. As our data show highly similar patterns of person agreement in German and Dutch, they also speak against a superficial explanation of the phenomenon as the one suggested by Corbett (1983: 183).

Let us now turn to a discussion of implications for psycholinguistic models of language production. First, the present data speak against a theory holding that person agreement in German and Dutch is computed by a purely syntactic mechanism using the resolution rules given in the introduction. If this were the case, all speakers should have provided almost exclusively 2 nd person plural responses. Furthermore, the results are not in line with a general principle on the application of resolution rules that has been suggested by Corbett (1983: 182):

When conjoined noun phrases show features which could trigger more than one type of resolution rule (e.g. person and number), then the normal choice is either to apply all the appropriate resolution rules, or to apply no resolution rule and to do the agreement with one conjunct only.

Obviously, our results show a different pattern. The resolution rule for number is consistently applied, that is, the two conjoined singular NPs are treated as a plural agreement controller, while the person resolution rule is not applied.

The present results strongly suggest that two different forces are at work, one based on a mechanism for computing person agreement favoring a 2nd person plural response and one based on a mechanism favoring a 3rd person plural response. In the following, we will offer some speculations as to what these two mechanisms could look like. The first mechanism is the two-step procedure already mentioned in the introduction, yielding a 2 nd person plural form of the verb or the reflexive pronoun. In a first step, the person features of the two elements of the compound subject are combined into a new person feature according to the resolution rules given above (see [3]). In the second step, this new person feature functions as the agreement controller for the verb inflection (German) or a reflexive pronoun marked for person (Dutch). In Experiment 2, this process of agreement computation even surfaces explicitly. Speakers quite often contract the two elements of the compound subject into one plural pronoun and only then complete the sentence.

What could the mechanism leading to a 3 rd person plural form on the verb or the reflexive pronoun look like? One possibility is that the 3rd 
Table 6. Number of reflexive pronouns observed for trials with 1 st and $3 \mathrm{rd}$ person element in Experiment 1 (Dutch)

\begin{tabular}{lllllllll}
\hline \multirow{2}{*}{ Condition } & Preamble & \multicolumn{3}{l}{ Uttered reflexive } \\
\cline { 3 - 8 } & & je/jullie & ons & & zich & & Error \\
\hline 1st + 3rd & ik en hij & 0 & $(0)$ & 30 & $(88)$ & 4 & $(12)$ & 6 \\
3 rd +1 st & hij en ik & 0 & $(0)$ & 33 & $(92)$ & 3 & $(8)$ & 4 \\
1 st + NP & ik en NPsing & 0 & $(0)$ & 30 & $(91)$ & 3 & $(9)$ & 7 \\
NP +1 st & NPsing en ik & 0 & $(0)$ & 33 & $(94)$ & 2 & $(6)$ & 5 \\
\hline
\end{tabular}

Note. Percentage of valid responses per condition in parentheses (excluding errors).

person has a special status. Whenever a sentence subject consists of a coordination of lexical elements, one of which has the feature 3rd person, the grammatical encoder has a strong tendency to use this value. Such a view can be linked to theoretical considerations suggesting that the $3 \mathrm{rd}$ person has a fundamentally different status from the 1st and 2nd person. For example, Lyons (1978: 638) argues that "the term 'third person' is negatively defined with respect to 'first person' and 'second person': it does not correlate with any participant role" (i.e. speaker for 1st person, and addressee for 2 nd person). If such an account in terms of 3 rd person functioning as a kind of default value were correct, then we should observe a similar phenomenon in coordinations of 1 st and 3rd person singular pronouns, that is, also for this type of compound subjects, speakers should have a tendency to use a 3rd person plural verb or reflexive. However, Experiment 1 reveals that this is not the case. Experiment 1 included filler trials with compound subjects consisting of a 3rd and a 1st person element (see description of materials above). The results for these trials are given in Table $6 .^{3}$

Obviously, for this type of compound subjects, there is hardly any tendency to respond with the 3rd person reflexive. Rather, in accordance with the rules for combining person features in (3), speakers almost exclusively produce the 1st person plural reflexive pronoun ons. Thus, we have to conclude that at least the data from Dutch can not be explained by assuming that the 3rd person functions as a kind of default value in case of conflicting person specifications in a compound subject. It should be noted, however, that our experiments do not provide us with corresponding direct evidence against the use of the 3rd person as a default in German. But given that Dutch and German are structurally very similar languages, it appears to be very unlikely that the 3rd person does not function as a default in Dutch, but does so in German. 
What else could the second route for computing person agreement look like? As point of departure, we note that recent psycholinguistic studies on number agreement (e.g. Bock et al. 1999) and gender agreement (e.g. Vigliocco and Franck 2001) suggest that the corresponding agreement processes can be affected by semantic-conceptual information. What type of semantic-conceptual information could be at work in the case of person agreement? In the following, we will offer some speculation on this question. First, we note that the feature "person" is not a fixed property of individuals or entities, because the same individuals or entities can be referred to using different person markings. Which person marking is appropriate depends on the discourse situation. There are three main roles in the discourse situation: speaker, addresee, and entity talked about. These roles are usually mapped onto the syntactic categories 1st person, 2nd person, and 3rd person, respectively. But what about a coordination of, for example, a 2 nd and a 3 rd person element? The coordination as a whole could either be conceived of as one adressee, or, alternatively, as one entity talked about. The latter option can be made clear by a coordination like "you and your car." It appears to be extremely unlikely that such a coordination is interpreted as one addressee. Given these considerations, the second route for agreement computation could consist of the following steps. In a first step, the speaker gives a coordination of a 2nd and a 3 rd person a conceptual-semantic interpretation as one entity talked about. This new conceptual entity is then in a second step mapped onto the syntactic category 3rd person. For a coordination of a 1st person and a 3rd person, such an interpretation as "entity talked about" is highly unlikely, as the 1st person has a highly specific conceptual interpretation - the speaker. Or put differently, the egocentric bias of the speaker blocks a conceptual-semantic reinterpretation of a compound subject containing a 1st person element as a new entity talked about.

Although admittedly speculative, additional evidence for this view can be obtained from examples with a compound subject and a possessive pronoun, like in (16):

(16) deine Frau und du haben (3rd plural)/habt (2nd plural) eure Eintrittskarten vergessen

(your wife and you have your tickets forgotten)

'you wife and you have forgotten your tickets'

According to our proposal, the compound subject can either be conceived of as addressee (following the resolution rule) or as entity talked about. In the case of the 2nd plural auxiliary habt, the compound subject is conceived of as addressee, and the 2 nd person plural possessive pronoun eure can be interpreted without problems as referring to this addressee. The 
3rd person plural auxiliary haben, by contrast, puts the compound subject in the role of "entity talked about." Because the role of addressee is thus not yet filled in, the 2 nd person possessive pronoun eure could either refer to the compound subject or to a third party who is actually treated as addressee. The difference between the construction with haben vs. habt becomes even more obvious when one stresses the possessive pronoun (deine Frau und du haben/habt EURE Eintrittskarten vergessen). Stressing the possessive pronoun in the version with the 3rd person plural auxiliary haben appears to trigger an interpretation assuming a third party fulfilling the role of addressee, while the version with the 2 nd person plural auxiliary sounds fairly unnatural.

Taken together, we propose that there are two procedures of computing person agreement between a compound subject and a verb. The first one is the two-step procedure already described above. This procedure makes use of a syntactic resolution rule for combining conflicting singular person features into a new plural person feature (see [3] above). In Experiment 2, this procedure even surfaces quite frequently in the main clause preambles. The second procedure works via a conceptual-semantic interpretation of the compound subject, which subsequently is mapped onto a person feature. This procedure can be related to the fact that the syntactic feature person has syntactic consequences (like person agreement between subject and verb), but is also a deictic category (e.g. Lyons 1968). It has even been argued that the deictic function of personal pronouns is more basic than their syntactic-anaphoric function (e.g. Lyons 1978, Chapter 15). This status of person as a deictic category appears to allow for strong nonsyntactic influences on the computation of person agreement. It remains an open issue for future research to determine which factors lead a speaker to adopt the one or the other procedure in a given situation.

Finally, we would like to briefly address two issues that provide interesting perspectives for future research in this area. First, it is not clear whether the interpretation of a compound subject with a 2 nd and a 3 rd person element as an entity talked about, as observed in the present study for Dutch and German, also holds for other languages, or whether languages differ in the relative strength of the two procedures for the computation of person agreement. Informal observation with native speakers of Italian, for example, suggests that for Italian compound subjects of the type used in the present experiments, the syntactic procedure clearly dominates. ${ }^{4}$

Second, at least in German, person agreement appears to be affected by the linear order of a compound subject and the agreement target (i.e. the verb and/or the reflexive pronoun). This can be exemplified by the following sentences taken from Drosdowski et al. (1972: 409). ${ }^{5}$ 
(17) Fernab des Verkehrs sonnten sich Far away from the traffic sun themselves

meine Frau und ich.

(verb, 3rd plural) (reflexive, 3rd plural)

my wife and I

'Far away from the traffic, my wife and I were taking a sunbath.'

While (17) is perfectly grammatical, the same sentence with a 1st person plural verb and reflexive, as in (18), appears to be odd:

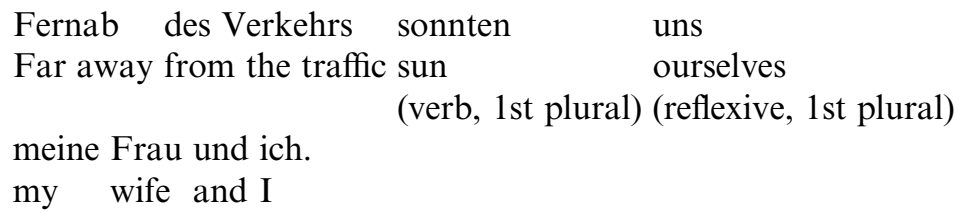

meine Frau und ich.

my wife and I

By contrast, when the compound subject (i.e. my wife and I) precedes the reflexive verb, both versions appear to be acceptable (e.g. meine Frau und ich sonnten sich/sonnten uns), with presumably a preference for the 1st person plural reflexive pronoun uns (see Table 6). Thus, it appears that agreement patterns can depend on the linear order in which subject and verb occur. Such variations of agreement patterns as a function of word order have also been observed for Arabic, and they do not only concern person agreement (see Aoun et al. 1994). If such a sensitivity of agreement processes to linear order can be firmly established in corresponding language production experiments, this would have important implications for psycholinguistic theories of language production. In particular, it has been claimed that agreement is computed in some kind of hierarchical syntactic representation, prior to the actual linearization of words for the eventual utterance (e.g. Vigliocco and Nicol, 1998). However, if this were the case, then agreement should be independent of the eventual linear order of words.

To conclude, the present experiments suggest that person agreement between a compound subject and a verb can be computed via two different procedures. We propose that one procedure is a purely syntactic procedure while the other procedure operates via a semantic-conceptual interpretation of the participant role of the compound subject. Furthermore, person agreement may turn out to be a domain in which agreement computation is sensitive to the eventual linear order of agreement controller and agreement target.

Received 19 April 2002

Revised version received

7 May 2003
University of Nijmegen

Boston University 


\section{Notes}

* We thank Rainer Dietrich for fruitful discussion of the topics addressed in this article, and for providing the possibility for collecting the data of Experiment 2. Correspondence address: Herbert Schriefers, NICI, University of Nijmegen, P.O. Box 9104, NL6500 HE Nijmegen, the Netherlands. E-mail: schriefers@nici.kun.nl.

1. In principle, this option was also available in Experiment 1. However, specifying the verb to be used before presenting the preamble appears to suppress such a tendency. As we will see in the present experiment, when the choice of the verb is completely free, participants use this option quite frequently.

2. The 3rd person plural responses could in fact also be 1st person plural responses because in German 1st and 3rd person plural verbs have identical forms. However, given that the preambles did not contain a 1 st person element, the corresponding responses can be taken to constitute 3 rd person plural inflections. This assumption receives further support from the results of Experiment 1. In this experiment, 1st, 2nd, and 3rd person plural were unambiguously marked on the corresponding reflexive pronouns. The results show that the 1st person plural is not considered as a valid choice.

3. Although the verbs specified on these filler trials did not obligatorily require a reflexive pronoun (see method section of Experiment 1), most responses included a reflexive pronoun. This is due to the selection of the corresponding verbs in such a way that they did not necessarily require a reflexive pronoun, but still had a strong bias towards use with a reflexive pronoun.

4. We thank Gabriella Vigliocco for collecting observations from native speakers of Italian.

5. The German reflexive verb sich sonnen is equivalent to the English expression "to take a sunbath." In addition to the actual translation, we also provide, in square brackets, a literal equivalent of the German sentence.

\section{References}

Aoun, Joseph; Benmamoun, Elabbas; and Sportiche, Dominique (1994). Agreement, word order, and conjunction in some varieties of Arabic. Linguistic Inquiry 25, 195-220.

Bock, Kathryn (1995). Producing agreement. Current Directions in Psychological Science 4, $56-61$.

-; and Eberhard, Kathleen (1993). Meaning, sound, and syntax in English number agreement. Language and Cognitive Processes 8, 57-99.

Bock, Kay; Nicol, Janet; and Cutting, J. Cooper (1999). The ties that bind: creating number agreement in speech. Journal of Memory and Language 40, 330-346.

Corbett, Greville (1983). Resolution rules: agreement in person, number, and gender. In Order, Concord and Constituency, G. Gazdar, E. Klein and G. K. Pullam (eds.), 175-205. Dordrecht: Foris.

—(1991). Gender. Cambridge: Cambridge University Press.

Drosdowski, Günther; Grebe, Paul; Köster, Rudolf; Müller, Wolfgang; and ScholzeStubenrecht, Werner (1972). Duden, Vol. 9: Zweifelsfälle der deutschen Sprache. Mannheim: Dudenverlag.

Findgren, Adne (1976). Zur Kongruenz in Person und Numerus zwischen Subjekt und finitem Verb im modernen Deutsch. Oslo: Universiteitsforlaget. 
Heijden, Emmeken van der (1999). Tussen nevenschikking en onderschikking. Doctoral dissertation, University of Nijmegen.

Kayne, Richard (1994). The Anti-Symmetry of Syntax. Cambridge, MA: MIT Press.

Lyons, John (1968). Introduction to Theoretical Linguistics. Cambridge: Cambridge University Press.

- (1978). Semantics. Cambridge: Cambridge University Press.

Munn, Alan (1993). Topics in the syntax and semantics of coordinate structures. Doctoral dissertation, University of Maryland.

Schriefers, Herbert; and Jescheniak, Jörg. D. (1999). The representation and processing of grammatical gender in language production: a review. Journal of Psycholinguistic Research 28, 575-600.

Vigliocco, Gabriella; and Franck, Julie (2001). When sex affects syntax: contextual influences in sentence production. Journal of Memory and Language 45, 368-390.

-; and Nicol, Janet (1998). Separating hierarchical relations and word order in language production: is proximity concord syntactic or linear? Cognition 68, B13-B29. 
Bereitgestellt von | Radboud University Nijmegen (Radboud University Nijm Angemeldet | 172.16.1.226

Heruntergeladen am | 24.02.12 12:43 